\title{
Constructing Knowledge and Technology Transfer Model for SMEs Technology Development in Emerging Economies
}

\author{
Handoko, F. ${ }^{1}$ \\ ${ }^{1}$ Industrial Engineering Department, National Institute of Technology (ITN), Indonesia \\ Corresponding Email: fourry@lecturer.itn.ac.id
}

\begin{abstract}
Technology innovations occur in stages. The stages begin by discovering scientific knowledge generated from basic research. The findings of basic research are used to generate developments associated with its 'applicability', and are then developed and tested in accordance with knowledge, economically relevant procedures, and technically sound (development process) procedures. Moreover, in-depth knowledge investigation (learning process) will produce innovation of equipment, processes, and products. Innovations will undergo a process of adaptation (adaptation process) in order to meet technical standards, productivity, and social influence of technology application. This paper constructs a model of sustainable knowledge and technology. The proposed model identifies the key factors of knowledge and technology transfer. The model was constructed based on system-based model of inputs-transformations-outputs.
\end{abstract}

Keywords: Technology Transfer; SMEs; Sustainable; On-going basis; Emerging economies

DOI: http://dx.doi.org/10.20961/ijpte.v1i2.15124 


\section{INTRODUCTION}

Small to medium enterprises (SMEs), particularly in emerging economies, are faced with a significantly complex external environment due to rapid technological evolution, globalisation and advanced competitors (Handoko, et al., 2014). SMEs that are involved in this environment must improve their performance in order to survive in the global marketplace (Handoko, et al, 2014). Successful competition requires a rapid response capability to provide goods or services for customer needs. In this environment, creating and maintaining competitive advantage through knowledge management systems has occurred widely (Handoko, et al., 2014; Davenport and Prusak 1998).

The aim of this study is to reconstruct the primary factors of sustainable knowledge and technology transfer and provide a contemporary theoretical and fieldwork support for these factors within the context of SMEs in developing economies. The success of any program that seeks to achieve a transfer of technology has a crucial dependency on external resources such as the transferor and the program itself. In particular, this research proposes the ideas of whether the knowledge and technology transfer program can be offered on a sustainable basis. It is contended that for the best results, technology transfer should not be performed in one-off programs; rather it must be performed on a sustainable basis.

\section{REQUIREMENT FOR TECHNOLOGY TRANSFER}

Knowledge and technologies play an essential part in maintaining opportunities for continuous improvement and innovation needed in the development of sustainable competitive advantage (Handoko et al., 2016; Gaynor, 1996; Cavusgil et al., 2003). However, the low capability of SMEs to provide the needed resources (e.g. human resources and facilitating technologies) is a barrier to the in-house development of their technological capability (Hong, 1994; Marino et al., 2001). Consequently, external resources to support their performance in developing technological capabilities, so-called 'knowledge and technology transfer' (Marcotte and Niosi, 2000; Gorman, 2003) programs, are needed. The process of knowledge and technology transfer involved the participation of active transferor. Government, businesses, and universities are well recognized as organisations, which have high concern in technology transfer program (Kremic, 2003; Lee, 1997; Friedman and Silberman, 2003; Graddy and Pratt, 2000). However, every technology supplier has distinct characteristics and motives (Kremic, 2003). The diversity of characteristics and motives will potentially affect the result, and indeed the success, of knowledge and technology transfer. It is important to manage any differences associated with the process of transferring knowledge and technology from government, universities and businesses to SMEs.

Knowledge and technology transfer needs to be sustainable, in that a transferor must be able to develop the receiving SME's technical capability and 
must support the associated learning process by which SME staff gain an understanding, if not mastery, of the technology. From the knowledge and technology transfer perspective, technical sustainability is crucial for development projects. In the absence of local capacity to maintain, repair and operate a technical system, external assistance simply becomes a one-time intervention. When the external knowledge resources have left, the project will ultimately be left to fail (Clemens et al, 2003; Mitchell, 1980; Francis and Mansell, 1988; Dudley, 1993; Carr, 1985).

\section{SUSTAINABLE TECHNOLOGY TRANSFER}

The essential argument sustainable technology transfer is that in the absence of transferee capacity to maintain, repair, operate and develop a technical system associated with a new technology, technology transfer becomes a one-time intervention (Clemens et al, 2003; Mitchell, 1980; Francis and Mansell, 1988; Dudley, 1993; Carr, 1985). It is imperative that an institution's upper-level management and local management be involved in technology transfer programs in dealing with social issues, for example with regard to how interventions that have been implemented can be sustained by the institution and through social interaction and structures (Crouch and Nimran, 1989).

Through technology transfer, a new knowledge and technology is adapted (adaptation process). The new adapted knowledge and technology can then improve the transferee technology capability. In-depth knowledge investigation (learning process) will produce process innovation. Innovations will undergo a process of adaptation (adaptation process) that will lead a process of innovation which then could be adapted again. The process of technology adaptation and innovation can then improve technology capability (Kemmis 2004, Rogers, 2003). Technical sustainability facilitates technology adaptation and technology innovation within SMEs (Clemens et al., 2003; Madanmohan et al., 2003). If successful, this process can then be repeated as needed within the SME (Said et al, 2001). In this way, the technical learning process can be completed in a sustainable basis (Kurokawa, 1997), by which it is possible to create selfsustaining in-house technology development.

In terms of the transferee organisation, new knowledge and technology that improve the technology capability are expected to build competitiveness and long-term profitability (Porter, 1998). Profitability is considered to be a reason for the transferee's organisation to support the (new) uptake of knowledge and technology transfer, asking the transferor to do more technology transfer in order to support further the transferee's organisation technology capability (Kremic, 2003). The entirety of a technology transfer program follows the logic of sustainable processes. With respect to the transferee organisation, sustainability is the on-going willingness of the organisation to be involved in technology transfer programs; and, in terms of transformation, the on-going process of adaptationinnovation-capability in order to obtain self-sustaining improvement. 
Technical sustainability facilitates technology adaptation and technology innovation within the SME (Clemens et al, 2003; Madanmohan et al., 2003). If successful, this process can then be repeated as needed within the SME (Said et al, 2001). In this way, the technical learning process is being completed in a sustainable manner (Kurokawa, 1997). Moreover, the learning process itself will provide a guide to sustainable technology transfer with which it is possible to create self-sustaining technology development. New technology that improves the long-term capability of a company is likely to encourage on-going knowledge and technology transfer. However, it is also important that SMEs observe increased competitiveness or profitability if the owners of SMEs are to support future uptake of knowledge and technology transfer. Since there may be several sources of motivation, it is necessary for these to be included in the construction of a model for sustainable technology transfer. The dependency of SMEs within developing economies on unexplained ('blackbox') technologies supplied by external transferors does not facilitate an on-going sustainable technology transfer. This research analyses the detail of the key factors and the crucial interactions between essential factors for sustainable technology transfer within the Javanese commercial environment, using comprehensive and integrated empirical measurements.

\section{SMALL TO MEDIUM ENTERPRISES}

SMEs are considered very important to the Indonesian economy (Hayashi, 2002). They have the capability to create employment, and are a valuable source of economic growth (Tambunan, 2005). As such, SMEs are important when completing a broad investigation into the process of industrialization (Hill, 2001).

The reasons why SMEs are an important subject in Indonesia include (after Hill, 2001, pp. 248-250):

1. SMEs play a pivotal role in generating an economy's development.

2. SMEs are a clear and consistently enunciated Indonesian government main concern. The government has given high priorities to SMEs for some decades.

3. Owing to impartiality issues - most likely because ethnic relations are very sensitive politically in Indonesia - SMEs have been used in promoting indigenous Indonesian business.

4. The imperative to formulate economy policy because it cannot be assumed that the same policies that are created for larger industrial units will necessarily apply to SMEs, because of SMEs-specific characteristics such as higher concentrations within particular industry sectors and less foreign ownership

5. The international experience indicates that efficient SMEs generate industrial growth and a flexible industrial structure. Taiwan often is held out as an example of an economy built on the foundations of an efficient SME sector (Hill, 2001). 
6. It is considered that SMEs in Indonesia are better able to accommodate economic crisis than LEs.

During the Asian economic crisis of 1997, SMEs demonstrated a greater capacity to continue operationing compared to LEs because of their flexibility in adjusting production processes in response to changing market demand, even though the economic changes were sudden (Tambunan, 2005).

During this crisis, SMEs in Indonesia were able to quickly change to new products and/or production settings. SMEs effectively used their existing linkages, and switched products to supply different market segments (e.g. the replacement market and the import substitution market). Regarding cost reduction in response to the economic crisis, SMEs increased their employment of school trainees to minimize their overall salary costs.

The number of Indonesia SMEs was estimated to be 42.4 million, and they contributed up to $56.7 \%$ of GDP, accounted for $19.4 \%$ of total exports, and employed 79 million people. In the Indonesian manufacturing sector, there were more than 2.5 million (99.9\%) manufacturing SMEs in 2005, compared to only 2,519 (0.1\%) manufacturing LEs (Indonesian Department of Cooperation and SMEs) and at this time, SMEs provided employment for approximately 8.5 million people ( $80 \%$ of those employed within the Indonesian manufacturing sector) compared to LEs employing approximately 2.4 million people (20\%).

Despite their important role in domestic economic and industrial development in Indonesia, SMEs increasingly have to actively compete in both regional and international trading markets. This is an environment with complex relationships, rapid technology enhancement, and competition.

In Indonesia, most SMEs operate using traditional methods of production and marketing. Lack of technological, managerial and marketing knowledge, and poor access to finance are the main impediments facing SMEs in Indonesia and elsewhere.

This lack of capital, lack of skills and lack of capabilities in business development are common problems for Indonesian SMEs. However, as other governments in the world have done to support SMEs in their countries, the Indonesian government, through its "Ministry for Cooperative and SMEs" have supported domestic SMEs by launching many programs, including programs associated with technology transfer and financial support (Ministry of Cooperative and SMEs).

\section{FIELDWORK RESEARCH}

Two episodes of fieldwork were conducted for this research. First, preliminary fieldwork was conducted to gain initial information about target areas of Central Java and East Java. Second, the fieldwork completed a survey to collect detailed data to build the proposition for proposed model. Data from peak industry bodies and government departments, such as the Agency for the Assessment and Application of Technology (BPPT) and information regarding national and 
provincial government policies from government departments, were sourced. Face-to-face interviews with SMEs and discussions with staff at a series of universities in Java are conducted. The fieldwork also searched for evidence of technology transfer that had previously occurred.

\section{Knowledge and technology transfer programs}

An example of knowledge and technology transfer for SMEs in Ceper was a project associated with the Divided Blast Cupola (DBC) (Handoko et al, 2014, 2017). "A cupola furnace is used in foundries to melt iron and some bronzes. The DBC introduces air blasts into the cupola through two levels of tuyeres, one above the other, in order to achieve a more efficient combustion of coke. Each row of tuyeres has its own wind box and air flow meters that controls individual air blasts. The upper airflow assists the combustion in the preheating area, and the lower airflow supports the combustion in the melting area" (Handoko et al., 2017).

BPPT made collaboration with the Metal Laboratory in Ceper and the technical expertise of the Japan International Coorperation Agency (JICA). To best exploit transferred technologies, associated issues for the SME workforce were identified, for example: (1) Engineering drafting; (2) Production Processes (Handoko et al, 2017).

Government-initiated knowledge and technology transfer in Indonesia is normally completed through government ministries and their associated agencies, inter-ministry departments and local government. Government provided training programs and expertise transfer, as well as physical equipment (machinery and tools) to SMEs (Handoko et al., 2017).

Large enterprises (Les) were found to be involved and provided highly focused training programs to SME employees. The programs have, for example, "sought to encourage improved capabilities in product standardisation, enabling SMEs to then supply products with the required quality to these larger businesses through improved competency (Handoko et al., 2017).

\section{Informal technology transfer}

Regarding informal Technology Transfer, collaboration also occurred when orders became urgent. Sharing knowledge among SME owners has occurred through informal meetings and gatherings (Handoko et el., 2017), for example, "Pengajian (gathering to pray together, usually on a weekly or monthly basis). The SME owners were found to share knowledge during such gatherings based on their particular skill, or when they had recently acquired a knowledge or skill" (Handoko et al., 2017) 


\section{PROPOSED MODEL OF SUSTAINABLE TECHNOLOGY TRANSFER}

A review of the relevant literature and the results of the preliminary fieldwork research were used as foundations to devise a proposed sustainable knowledge and technology transfer model research that will assist the creation of a proposed computational model. Factors affecting sustainable knowledge and technology transfer are explored to identify the relationships among those variables that support the proposed model. A systematic and consistent process is applied. The main constructs are identified and relationships between constructs are extracted. The results of these analyses will be presented in diagrammatic form.

\section{System-based structured analysis process}

A systematic approach has been developed to analyse the proposed constructs, and the relationships among those constructs as supporting factors to create the proposed model. The adoption of a systems-based approach offers several advantages. For example, the identification of the system (in all its complexity), its components (people, machines, requirements, priorities, and the extent to which they all have been satisfied is enabled (Weinber, 1980; Singh, 2002). The structured analysis approach was developed by De Marco (Singh, 2002), and identifies logical or conceptual relationships among the desired system output, the data used in the system, and the system's inputs (Cushing and Romeny, 1990; Singh 2002). When applied to the development of systems, the structured analysis approach produces a graphical representation, composed of a variety of diagrams with associated partitioning. Individual portions of the associated specification can be read independently of other portions (Yourdon, 1989). The features of structural analysis are eminently suitable for describing the underlying theory of sustainable techno logy transfer (Singh, 2002).

\section{Construct groups of knowledge and technology transfer}

In order to identify the key components of knowledge and technology transfer constructs, the available literatures on knowledge and technology transfer, and the findings of the preliminary fieldwork, have been critically analysed. The list of construct groups is: 'stakeholders', 'knowledge', 'processes', and 'outcomes'. These construct groups were sufficiently comprehensive to ensure that the important aspects of knowledge and technology transfer were covered.

Stakeholders

The first construct group that has emerged, as part of the structured analysis process, is the 'stakeholders'. Donaldson and Preston (1995: page 67) describe the stakeholder theory of the firm as:

Stakeholders are persons or groups with legitimate interests in procedural and/or substantive aspects of corporate activity. Stakeholders are identified by their interests in the corporation, whether the corporation has any 
corresponding functional interest in them. The interests of all stakeholders are of intrinsic value. That is, each group of stakeholder's merits consideration for its own sake and not merely because of its ability to further the interests of some other group, such as shareowners.

Another description of a stakeholder is from Clarkson (1995: page 106) gives a narrower definition, as follows:

Stakeholders are persons or groups that have, or claim, ownership, rights, or interests in a corporation and its activities, past, present, or future. Such claimed rights or interests are the result of transactions with, or actions taken by, the corporation, and may be legal or moral, individual or collective. Stakeholders with similar interests, claims, or rights can be classified as belonging to the same group: employees, shareholders, customers, and so on.

This definition results in the opposite problem of being excessively restrictive in scope (Singh, 2002). In the absence of an agreement on what constitutes the 'stakeholder', with various authors using the terms stakeholder in very different ways, this research adopts the pragmatic approach based on 'The Stakeholder Model' (Donaldson and Preston, 1995), where the stakeholders of an organisation could include: owners/shareholders, the top management leadership group, suppliers, regulators and government, including communities. In terms of knowledge and technology transfer and SMEs, the transferors, who are treated as the stakeholders, include the government, universities, and business organisations.

In the model being developed in this research, the government is given the task of ensuring their investment in research and technology is delivered to the public in a way that is of practical benefit (Kremic, 2003). Businesses have to understand the social responsibility aspects of their role, and by the nature of capitalist enterprise, have to obtain their products to an acceptable standard from a reliable source to support their industry (Tambunan, 2005; 2009). Supporting outsourcing (in particular, engaging SMEs) is a means of obtaining 'requirement products'. Universities are often required to be involved in knowledge and technology transfer programs as a part of the university's mission to transfer knowledge to the community and to acquire experience about practical problems useful for teaching, and to collaborate with other universities and government (Lee, 1997).

\section{Input}

The second broad construct group is 'input'. This construct group represents that which is to be transferred. The inputs can be traditional resources such as labor, equipment and raw materials, or can also be non-traditional resources in the form of knowledge and skills (Samson and Singh, 2008; Singh, 2002). This research seeks to explore the nature of the technology transfer program. As noted earlier, some researchers have identified the difficulty of separating technology transfer per se from knowledge transfer. In the proposed model, this is acknowledged by the use of codified and tacit knowledge as 'input'. 


\section{Processes}

The next broad construct group is 'processes'. This construct represents the main activities in knowledge and technology transfer. The fact that the scope of this research is narrowed to knowledge and technology transfer programs provides some relief in generating the list of transferring processes. Reviewing knowledge and technology transfer, and the stages of technology development literature suggests that the following processes are the principal determinants of successful technology transfer programs: adaptation, process innovation (Khalil, 2000; Singh, 2002; Kemmis, 2005). The quality management and technology management literature advocates that processes need to be continually improved for them to retain competitive advantage (Potter, 1998; Schlie, 2000; Singh, 2000) and profitability (Potter, 1998).

\section{Outputs}

The final broad construct group is the expected 'outputs' of the processes of knowledge and technology transfer. As technology transfer is considered to be a shortcut to developing technology capability, technology capability is included in the outcomes. Other outcomes include financial and non-financial performance. The construct associated with financial performance is profitability, and the constructs associated with non-financial performance are competitiveness (Flynn, et al., 2003) and (technology based) future uptake programs (Kremic, 2003). In this research, (technology based) future uptake programs correspond to the willingness of the transferee to adopt further technology transfer programs.

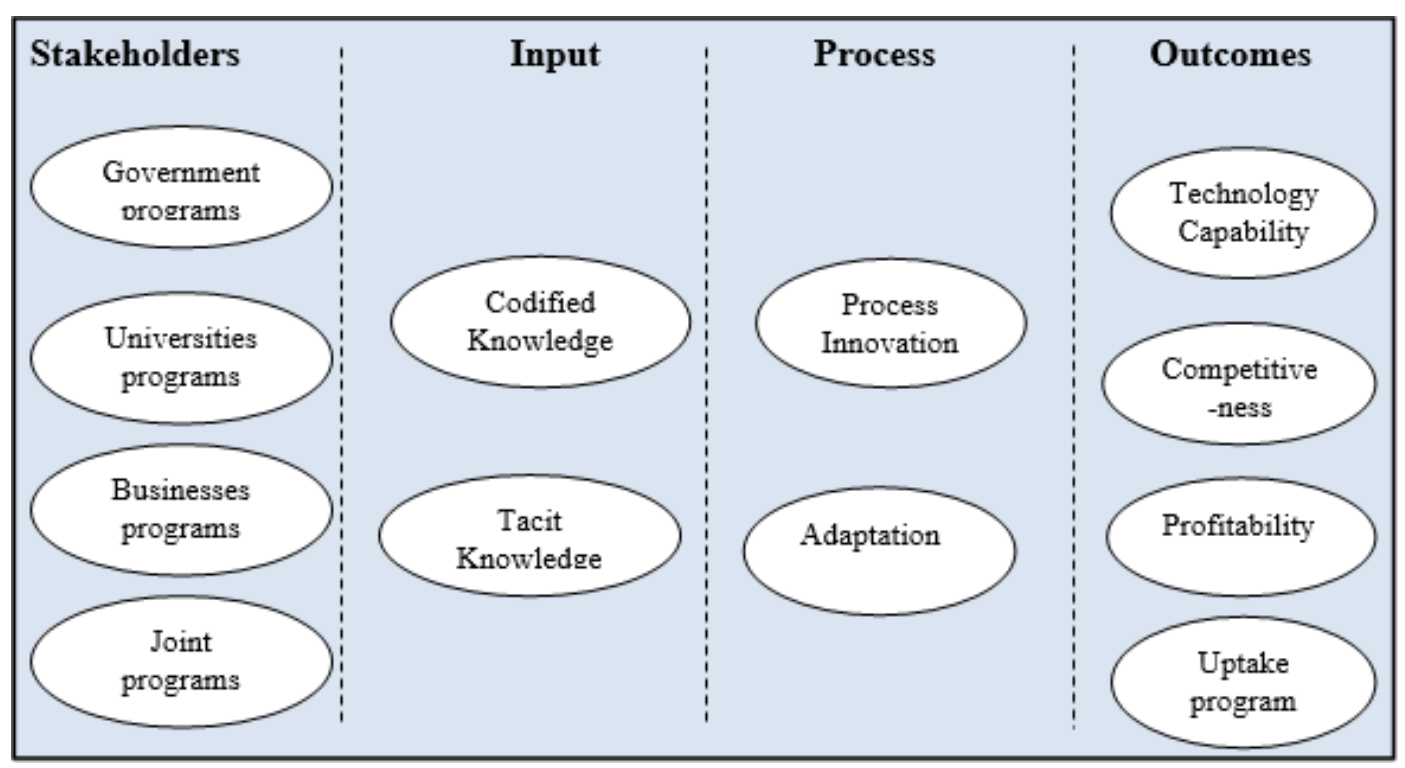

Fig. 1: Schematic of analysis framework to determine a model of the sustainable technology transfer 


\section{Analysis Framework of the Model}

The results of the structured analysis process that have been presented in the preceding section can be summarised in diagrammatic form (Figure. 1). The relevant constructs of each of the construct groups are shown as part of the analysis framework. The systems-based structured analysis process results in an analysis framework that can identify all the salient constructs of knowledge and technology transfer; cluster the constructs into logical broader groups and present these groups and constructs in a descriptive, graphical form (Figure 2). The analysis framework ensures that there is consistent analysis of the sustainable technology transfer approach. To determine the underlying theoretical model of sustainable and technology transfer, the relevant literature has been analysed to identify the key approaches and to determine the relationships among constructs.

\section{Sustainable Technology Transfer Model}

The value of an integrating framework for investigating the breadth of technology transfer was identified in the underlying theories. Stakeholders, Inputs, Processes and Outcomes are the list of construct classifications that are deemed to be sufficiently comprehensive to ensure that all salient aspects of sustainable technology transfer are covered.

\section{Stakeholder}

In the process of technology transfer, the transferors (i.e. government, business, university) that are treated as stakeholders, who apply a technology transfer program, which is considered an input within the proposed model. Of course, a transferor can initiate or participate in more than one program.

\section{Input-Process}

A technology transfer program is considered a rapid means of elevating the technology capability of a SME and, as a consequence, the relationship between construct groups can be modeled. In case of tacit and codified knowledge, the available literature suggests that the relation between knowledge and the technology transfer process takes place through the adaptation of the transferee (Niosi, 2002; Vandana, 2004).

\section{Transfer-Processes}

Within the processes of knowledge and technology transfer, it is possible that adaptation and process innovation have direct relationships to one another. These direct relationships represent the process of technology development (Handoko et al, 2016; Khalil, 2000; Kemmis, 2000). 


\section{Process-Outcomes}

When technology improvement occurs, there is the potential for greater levels of customer satisfaction with the potential for an associated improvement to technology capability, competitiveness, and profitability (Porter, 2000; Schlie, 2000; Lin, 2004).

\section{Between outcomes}

Examination of the available literature and the preliminary research survey completed by the author suggest that a direct relationship exists between:

- competitiveness and technology uptake programs, and

- profitability and the technology uptake program.

An analysis of the available literature and preliminary fieldwork has led to the model of sustainable technology transfer shown in Figure 2 and the associated interrelationships. The model follows the conditions of identifying the technology transfer 'system' and its boundaries, identifying the constructs of knowledge and technology transfer, clustering these constructs into logical broader groups, and presenting these groups and constructs in descriptive and graphical form.

The key stakeholders within sustainable technology transfer are the transferors and transferees, who enable transformation processes associated with adaptation and process innovation. The successful transformation process generates the expected outcomes of technology capability, competitiveness and profitability. Profitability, in turn, has the capacity to encourage a policy of further uptake of technology transfer programs.

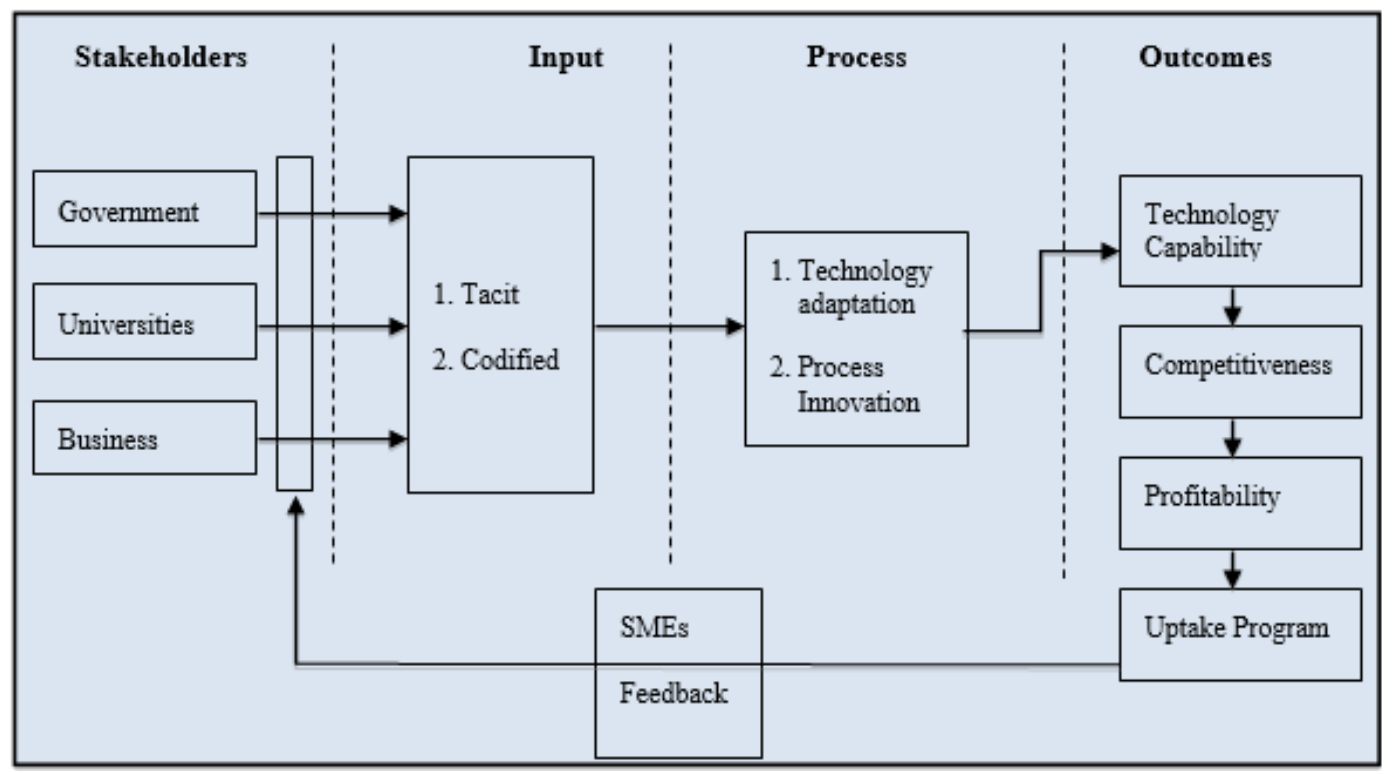

Fig. 2: Model for sustainable technology transfer 


\section{CONCLUSION}

The research has sought to identify the primary factors that can lead to sustainability of knowledge and technology transfer; their impacts and how they are interrelated. The key factors of the model were rigorously constructed. The underlying theories of key factors to build the sustainable technology transfer model were extracted from the available relevant literature and preliminary fieldwork findings. It is proposed that for the best results, technology transfer should not be performed in one-off programs; rather it must be performed on a sustainable basis. Otherwise, in the absence of a transferee capacity to maintain, repair, operate and develop a technical system encompassing the new technology, technology transfer becomes a short-term intervention. Once the transferor leaves, the project will eventually be left to fail.

The model in figure 2 is constructed from the literature and fieldwork evidences gathered and analysed in this research. In-house transformation leads to selfsustaining technology development inside the organisation. The new technology received through technology transfer is adapted by the organisation. Organisations that then create technology development do so through adapting technology and process innovation to elevate the SME's technological capability. The profitable technology received through the technology transfer program must be continuously developed to create better organisational technology capability. This model is also valuable for the transferor organisation to use as technology transfer effectiveness criteria with regard to transferor technology transfer programs. Whilst not specifically tested for, it should be clear that organisations must establish a strategy driven by a policy that is committed to continual technology transfer. Without the commitment to continue to undertake these programs, in the long-term it will not matter how effective any one program is.

\section{REFERENCES}

Alavi,M., and Leidner,D. 2001. Knowledge management and knowledge management systems: Conceptual foundations and research issues. MIS Quarterly, 25 (1), 107.

Carr, M,. (Ed) 1985. The AT Reader: Theory and Practice in Appropriate Technology. London: Intermediate Technology Publication Ltd, in Clemens et al.

Cavusgil, S.T., Calantone, R.J., and Zhao, Y., 2003; Tacit Knowledge Transfer and Firm Innovation Capability. Journal of Business and Industrial Marketing.

Chandra, Vandana. 2006; Technology, adaptation, and exports: how some developing countries got it right. Washington, DC: World Bank, 2006.

Clarkson, M.B.E., 1995; a Stakeholder Framework for Analysing and Evaluating Corporate Social Performance. Academy of Management Review. Vol.20, No.1, pp.92-117.

Clemens, 2003 The People's Water: Technology Transfer and Community Empowerment in Guatemala. Research in Science and Technology Studies, Vol.13, p. 105-127.

Cushing, B.E., and Romeny, M.B., 1990; Accounting Information System: A Comprehensive Approach. Reading, Mass: Addison-Wesley.

Davenport,T.H., Prusak,L., 1998. Working Knowledge: How Organizations Manage What They Know. Boston: Harvard Business School Press.

Donaldson, T., and Preston, L.E., 1995; The Stakeholder Theory of the Corporation: Concepts, 
Evidence, and Implications. Academy of Management Review. Vol.20, No.1, pp.65-91.

Drucker, P. 1994. The age of social transformation. The Atlantic Monthly, 274(5), 53-70.

Dudley, E.1993. The Critical Villager: Beyond Community Participation. London: Routledge, in Clements et al (2003).

Flynn, B.B., Shroeder, R.G., and Sakakibara, S., 1994; A framework for quality management research and associated measurement instrument. Journal of Operations Management. Vol.11, pp.339-366.

Francis, A. J., \& Mansell, D. S., 1988. Appropriate Engineering Technology for Developing Countries. Victoria, Australia: Research Publications Pty. Ltd, in Clements et al. Freeman, R.E., 1984; Strategic Management: A Stakeholder Approach. Boston: Pitman.

Friedman, J. and Silberman, J. (2003). University Technology Transfer: Do Incentives, Management, and Location Matter? Journal of Technology Transfer.

Gaynor, Gerard H, 1996. Handbook of Technology Management. McGraw-Hill. International Edition, United States of America.

Gorman, M. E., 2003; Types of Knowledge and Their Roles in Technology Transfer. The Journal of Technology Transfer, 27(3), 219-231.

Grady, R., \& Pratt, J., 2000. The UK Technology Transfer System: Calls for Stronger Links between Higher Education and Industry. The Journal of Technology Transfer, 25(2), 205211.

Handoko, F., Alan, S., and Burvill, C., 2014. The Role of Government, Universities, and Business in Advancing Technology for SMEs' innovation. Journal of Chinese Economic and Business Studies. Vol 12, No. 2. pp171-180.

Handoko, F., Nursanti, E., Harmanto, D., and Sutriyono, 2016. Technology Transfer for Metal Based SMEs in Central Java, Indonesia. ARPN Journal of Engineering and Applied Science, Vol. 11., No. 8.

Handoko, F., Smith, A., Indriani, S., 2017. The role of Tacit and Codified Knowledge within Technology Transfer Program on Technology Adaptation. International Journal of Engineering and Management (IJEM), Vol. 1, No. 1, Aug, 2017 pp.35

Hill, 2001; "Small and Medium Enterprises in Indonesia: Old Policy Challenges for a New Administration", Asian Survey, 41:2, pp. 248-270.

Hong, Jon-Chao, 1994. Technology Transfer and Human Resource Development. Industrial and Commercial Trainning, Vol. 26 No. 11, 1994, pp. 17-21. MCB University Press, 00197858

Iivari, J., Hirschheim,R., and Klein, HK., 2001; A Dynamic Framework for Classifying Information Systems Development Methodologies and Approaches. Journal of Management Information Systems. Vol.17, No.3, pp.179-218.

Johnson, S. D., Gatz, E. F., \& Hicks, D. (1998). Expanding the content base of technology education: Technology transfer as a topic of study. Journal of Technology Education, 8(2), 35-49.

Kemmis, S. and McTaggart, R., 2005; Research: Communicative Action and the Public Sphere. Chapter 23 in Denzin, N. and Lincoln, Y. (eds.) Handbook of Qualitative Research, $3^{\text {rd }}$ edition. Thousand Oaks, California: Sage.

Kemmis, S., and McTaggart, R., 2000; Research. In N. Denzin and Y. Lincoln (Eds.) Handbook of Qualitative Research, $2^{\text {nd }}$ edition. Beverly Hills, Calif. Sage.

Khalil, 2000; The Key to Competitiveness and Wealth Creation. Management of Technology. Mc.Graw Hill.

Klapwicjk, M. Rural Clusters in Java, Indonesia: An Empirical Assessment of Their Role in Industrialization. Ph.D. Dissertation, Timbergen Institute Research Series no 153, Vrije Universitiet Amsterdam, 1997.

Kremic, T., 2003; Technology Transfer: A Contextual Approach. The Journal of Technology Transfer, 28(2), 149-158.

Kurokawa, S., 1997, "Make-or-Buy Decisions in R\&D: Small Technology Based Firms in the United States and Japan. IEEE Transactions on Engineering Management, vol.44, No.2

Lee, Yong S., and Gartner, R., 1997; Translating Academic Research to Technological Innovation. Quorum Books, Westport, Connecticut, London

Madanmohan et al, 2003. Import-led technological capability: a comparative analysis of Indian 
and Indonesian manufacturing firms. Technovation 24 (2004) 979-993.Elsevier

Marcotte, C., Niosi, J., 2002; Technology Transfer to China. The Issues of Knowledge and Learning. The Journal of Technology Transfer, 25(1), 43-57.

Marino et al, 2001. "Harnessing Complexity: The Moderating Effect of National Culture on the Relationship between Entrepreneurial Orientation and Strategic Alliance Portfolio Complexity", Department of Management and Marketing Tuscaloosa, pp: 1-19.

Mitchell, R. J., 1980. Experiences in Appropriate Technology. Ottawa, Canada: The Canadian Hunger Foundation.

Porter, M.E., 2008. "Competitive Advantage": Creating and Sustaining Superior Performance. The Free Press. (Revision).

Samli, A. Coskun, 1985; Technology Transfer: Geographic, Economic, Cultural, and Technical Dimensions. (Westport, Conn., Quorum Books).

Sandee, H., and Pie Rietveld, 2001; upgrading traditional technologies in small-scale industry clusters: Collaboration and innovation adoption in Indonesia. The Journal of Development Studies. London: Apr 2001. Vol. 37, Iss. 4; p. 150 (23 pages).

Schlie, 1996; the Contribution of Technology to Competitive Advantage. Handbook of Management of Technology. Mc. Graw Hill.

Schmitz, H., and Nadvi, K., 1999; Clustering and industrialization: introduction to the special issue. Worl Development.

Singh, Prakash J. 2002. A Study of Theoretical and Empirical Bases of Operationalising Popular Quality Management Approaches in Manufacturing Organizations in Australia. PhD Dissertation.

Tambunan, T., (2011) "Development of small and medium enterprises in a developing country: The Indonesian case" Journal of Enterprising Communities: People and Places in the Global Economy, Vol. 5 Iss: 1, pp.68 - 82.

Tambunan, T., 2005; Promoting Small and Medium Enterprises with a Clustering Approach: A Policy Experience from Indonesia. Journal of Small Business Management. Milwaukee: 43, 138.

Yourdon, E., 1989 Modern Structured Analysis. New Jersey: Prentice-Hall. 